\title{
Numerical Study of the Geometry Effect of Notched Connections in Mass Timber Panel-Concrete Composite Floors
}

\author{
Lei Zhang ${ }^{1}$ and Y H Chui ${ }^{2 *}$ \\ ${ }^{1}$ PhD student, Department of Civil and Environmental Engineering, University of Alberta \\ ${ }^{2}$ Professor, Department of Civil and Environmental Engineering, University of Alberta \\ *Corresponding author's e-mail: yhc@ualberta.ca
}

\begin{abstract}
A mass timber panel-concrete (MTPC) composite floor system consists of a timber panel in the tensile zone, a concrete layer in the compression zone, and shear connectors between timber and concrete. The notched connections that are cut in timber and connected with concrete by the interlocking effect are often classified as the best type of connection system in terms of stiffness and load-carrying capacity. To study the effect of notch geometry to the performance of notched connections and composite beams, 2D finite element models are built in ABAQUS in this study. The concrete portion is modelled with concrete damaged plasticity model while the timber portion is modelled with Hashin's failure criteria. The effective bending stiffness and ultimate bending capacity of the composite beam under uniformly distributed load are obtained from the finite element models and are compared with the well-known Gamma method in Eurocode 5 and strut-and-tie model. Good agreement between finite element model in the elastic range and strutand-tie model was achieved. However, due to the assumptions made in the Gamma method, it was found that this simplified design method is not capable of describing MTPC composite floors with discrete notched connections.
\end{abstract}

\section{KEYWORDS}

Mass timber panel-concrete composite floor; Notched connection; Concrete damaged plasticity model; Hashin's failure criteria; Gamma method; Strut-and-tie model

\section{INTRODUCTION}

Mass timber panel-concrete (MTPC) composite floor system is a construction technique in which the timber deck at bottom is connected to an upper concrete layer with shear connectors. The coupling of a timber layer at tensile zone and a concrete layer at compression zone allows best utilization of both materials. The performance of MTPC composite floor is largely governed by the efficiency of shear connectors between two layers. Among a wide range of the connecting system, the notched connection is one of the most efficient connections that provide low interlayer slip and high resistance from its interlocking effect (Yeoh et al., 2010).

The geometry of notched connections is one of the most important factors that contributes to the variation of stiffness, strength and failure mode of the joint. Although some guidelines about the notched connection design have been proposed based on test investigations (Dias et al., 2018), those are not well accepted in practice. This study investigates the effects of some important geometry factors to the performance of the notched connections and the composite beams 
through numerical analysis. Results from the numerical analysis are compared with two analytical models to evaluate their accuracy in describing the MTPC composite floors with notches.

\section{FINITE ELEMENT MODELING OF THE NOTCHED CONNECTIONS}

\section{Geometry of the notched connections}

The notched connections in MTPC composite floors are made by cutting grooves in timber and cast concrete on top of timber. In this study, only the rectangular notches are considered, as shown in Figure 1. The geometry parameters of a rectangular notched connection including the length of the notch $l_{c}$, the length of timber in front of the notch $l_{t}$ and the depth of the notch $h_{n}$.

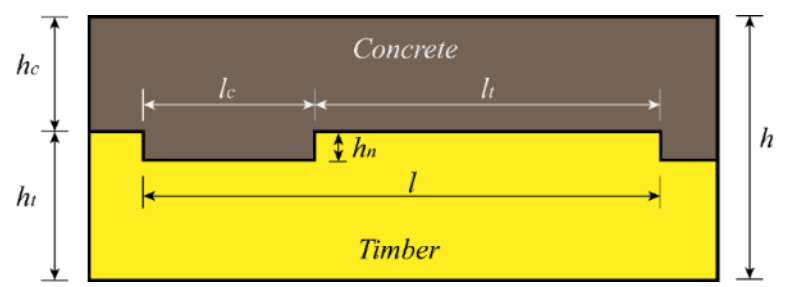

Figure 1. Geometry of a rectangular notched connection

Two-dimensional finite element models of the notched connections are built in ABAQUS to study the properties, including stiffness, strength and failure mode, of the connections subjected to shear load. The depths of timber and concrete layers are set as $130 \mathrm{~mm}$ and $100 \mathrm{~mm}$ respectively and their widths are set as $200 \mathrm{~mm}$. The depth of the groove is fixed as $25 \mathrm{~mm}$ in all the samples as suggested by Dias et al. (2018). The length of the groove $l_{t}$ and length of timber in front of the groove $l_{c}$ are varied in different models, as shown in Table 1.

Table 1. Geometry of the connections

\begin{tabular}{cccccc}
\hline Group & Length ratio* & Sample & Timber length $l_{t} / \mathrm{mm}$ & Notch length $l_{c} / \mathrm{mm}$ & Total length $l / \mathrm{mm}$ \\
\hline \multirow{2}{*}{1} & \multirow{2}{*}{$1: 1$} & $1-1$ & 50 & 50 & 100 \\
& & $1-2$ & 100 & 50 & 150 \\
& & $1-3$ & 150 & 50 & 200 \\
\hline \multirow{3}{*}{2} & $2: 1$ & $2-1$ & 100 & 100 & 200 \\
& & $2-2$ & 200 & 100 & 300 \\
3 & $3: 3$ & $3-1$ & 300 & 100 & 400 \\
& \multirow{3}{*}{3} & $3-2$ & 150 & 150 & 450 \\
& & $3-3$ & 300 & 150 & 600 \\
\hline
\end{tabular}

Length ratio: the ratio of timber length $l_{t}$ to the concrete length $l_{c}$ (notch length).

\section{Material properties of timber}

Spruce-pine-fir glued laminated timber (GLT) is assumed as the timber deck in this study. In the FE models, timber is modeled as transverse isotropic in the elastic range and Hashin's failure criteria (Hashin, 1980) is used to predict its onset of failure. The Hashin's failure criteria was initially proposed to describe the yielding of fibre reinforced composite materials but researchers have also used this criteria in the wood modeling since wood has a similar microstructure as fibre reinforced composite materials. The Hashin's failure criteria considers four failure modes of the 
material, namely fiber compression failure, fiber tensile failure, matrix compression failure and matrix tensile failure.

The input material properties for timber are taken from wood handbook (USA Forest Products Laboratory, 2010) and are listed in Table 2. The tension strength perpendicular to grain and fracture energies of timber are assumed as there is currently no published data.

Table 2. Material properties of timber

\begin{tabular}{|c|c|c|c|c|c|}
\hline \multicolumn{6}{|c|}{ Elastic constants [MPa for $\mathrm{E}$ and $\mathrm{G}]$} \\
\hline $\mathrm{E}_{\mathrm{L}}$ & $\mathrm{E}_{\mathrm{T}}$ & $\mathrm{Nu}_{\mathrm{LT}}$ & & & $\mathrm{G}_{\mathrm{TT}}$ \\
\hline 11200 & 745 & 0.42 & & & 37 \\
\hline \multicolumn{6}{|c|}{ Strength $[\mathrm{MPa}]$} \\
\hline$F_{t}^{L}$ & $F_{c}^{L}$ & $F_{t}^{T}$ & $F_{c}^{T}$ & $S^{L}$ & $S^{T}$ \\
\hline 67 & 37.8 & 2.5 & 4.1 & 6.8 & 1.6 \\
\hline \multicolumn{6}{|c|}{ Fracture Energy $[\mathrm{N} / \mathrm{mm}]$} \\
\hline $\begin{array}{c}\text { Longitudinal Tension } \\
5\end{array}$ & & Comp & Transve & & $\begin{array}{c}\text { Transverse Comp } \\
1\end{array}$ \\
\hline
\end{tabular}

\section{Material properties of concrete}

The concrete in the FE models are modeled with concrete damaged plasticity (CDP) model. The behaviour of concrete under compression and tension are shown in Figure 2.

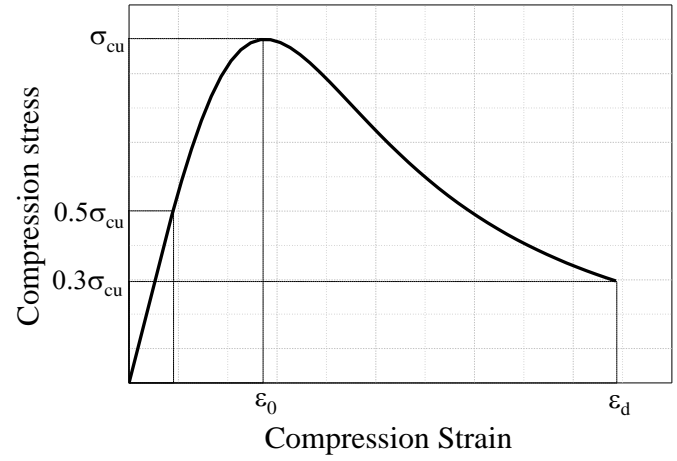

(a) Stress-strain behaviour under compression

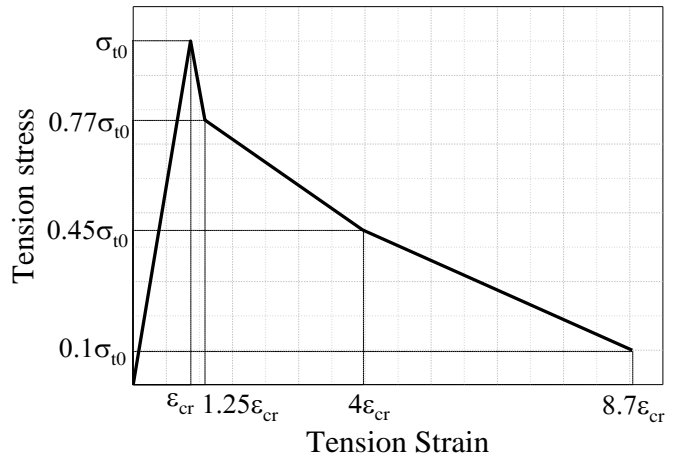

(b) Stress-strain behaviour under tension

Figure 2. Stress-strain behaviour of concrete

The stress-strain curve of concrete under compression is derived using the model proposed by Hsu and Hsu (1994) which allows for the development of the complete stress-strain curve only using the maximum compressive strength (which is assumed to be $50 \mathrm{MPa}$ in this study). After an initial linear stress-strain relationship up to the yield point (which is assumed to be $50 \%$ of the ultimate compressive strength) in the ascending portion, the compressive stress afterwards obeys

$$
\sigma_{c}=\left(\frac{\beta\left(\varepsilon_{c} / \varepsilon_{0}\right)}{\beta-1+\left(\varepsilon_{c} / \varepsilon_{0}\right)^{\beta}}\right) \sigma_{c u}
$$

until the stress descends to $0.3 \sigma_{c u}$. In equation (1),

$$
\begin{gathered}
\beta=\left\{1-\left[\sigma_{c u} /\left(\varepsilon_{0} E_{0}\right)\right]\right\}^{-1} \\
\varepsilon_{0}=8.9 \times 10^{-5} \sigma_{c u}+2.114 \times 10^{-3} \\
E_{0}=1.2431 \times 10^{2} \sigma_{c u}+3.28312 \times 10^{3}
\end{gathered}
$$

In the above equations, $\sigma_{c}, \sigma_{c u}$ and $E_{0}$ are in units of kip/in ${ }^{2}$. 
MOC SUMMIT / MAY 2019

Table 3. Material properties of concrete

\begin{tabular}{ccccc}
\hline & $\mathrm{E} / \mathrm{MPa}$ & \multicolumn{3}{c}{$\mathrm{Nu}$} \\
& 28852 & & $\mathrm{~K} 2.19$ \\
\hline Dilation angle & Eccentricity & $\mathrm{fb}_{0} / \mathrm{fc}_{0}$ & $\mathrm{~K}$ & Viscosity Parameter \\
36 & 0.1 & 1.16 & 0.667 & 0.001 \\
\hline
\end{tabular}

The tension stress-strain relation of concrete shown in Figure 2(b) is adopted from Wahalathantri et al. (2011). The tensile strength is assumed to be $10 \%$ of the compressive strength. The input material properties of concrete are shown in Table 3. Friction coefficient between timber and concrete is set as 0.62 .

\section{Results and discussion}

The load-displacement curves of the notched connections under shear load are shown in Figure 3. The applied load is almost linearly increasing before the peak load is reached. The stiffness, strength and failure mode for different connections obtained from FE analysis are listed in Table 4.

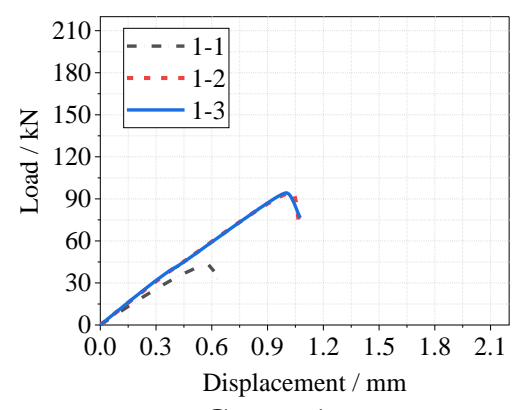

Group 1

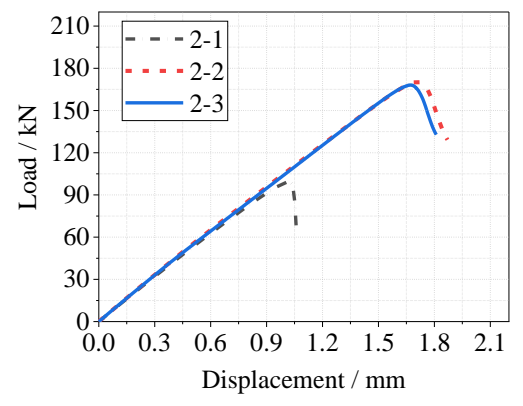

Group 2

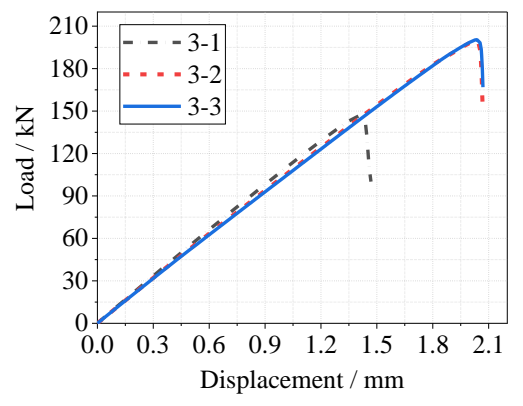

Group 3

Figure 3. Shear load-slip curves for different notched connections

Table 4. Notched connection FE modeling results

\begin{tabular}{|c|c|c|c|c|c|}
\hline \multirow[b]{2}{*}{ Sample } & \multicolumn{2}{|c|}{ Absolute } & \multicolumn{2}{|c|}{ Normalized } & \multirow[b]{2}{*}{ Failure mode } \\
\hline & $\begin{array}{l}\text { Stiffness } \\
\mathrm{kN} / \mathrm{mm}\end{array}$ & $\begin{array}{l}\text { Strength } \\
\mathrm{kN}\end{array}$ & $\begin{array}{l}\text { Stiffness } \\
\mathrm{kN} / \mathrm{mm}^{2}\end{array}$ & $\begin{array}{l}\text { Strength } \\
\mathrm{kN} / \mathrm{mm}\end{array}$ & \\
\hline $1-1$ & 87.64 & 43.05 & 0.876 & 0.431 & Timber shear failure \\
\hline $1-2$ & 101.88 & 94.38 & 0.679 & 0.629 & $\begin{array}{l}\text { Concrete tensile cracking followed by } \\
\text { concrete shear failure and timber shear failure }\end{array}$ \\
\hline $1-3$ & 102.34 & 94.30 & 0.512 & 0.472 & $\begin{array}{l}\text { Concrete tensile cracking followed by } \\
\text { concrete shear failure }\end{array}$ \\
\hline $2-1$ & 105.67 & 99.20 & 0.528 & 0.496 & Timber shear failure \\
\hline $2-2$ & 107.09 & 170.25 & 0.357 & 0.567 & $\begin{array}{c}\text { Concrete tensile cracking followed by } \\
\text { concrete shear failure and timber shear failure }\end{array}$ \\
\hline $2-3$ & 104.24 & 168.11 & 0.261 & 0.420 & $\begin{array}{l}\text { Concrete tensile cracking followed by } \\
\text { concrete shear failure }\end{array}$ \\
\hline $3-1$ & 110.10 & 146.58 & 0.367 & 0.489 & $\begin{array}{l}\text { Concrete tensile cracking followed by timber } \\
\text { shear failure }\end{array}$ \\
\hline $3-2$ & 103.31 & 199.51 & 0.230 & 0.443 & $\begin{array}{l}\text { Concrete tensile cracking followed by timber } \\
\text { compression failure }\end{array}$ \\
\hline $3-3$ & 102.11 & 200.43 & 0.170 & 0.334 & $\begin{array}{l}\text { Concrete tensile cracking followed by timber } \\
\text { compression failure }\end{array}$ \\
\hline
\end{tabular}


In Table 4, the stiffness of the joint is taken as the slope of the load-displacement curve between $10 \%-40 \%$ of the peak load according to EN 26891(CEN 1991), which could be considered as the serviceability stiffness. The normalized stiffness and normalized strength are obtained by dividing the stiffness and strength by the total length of the joint. The variation of stiffness and strength with total connection length is illustrated in Figure 4. Also shown in Figure 4 is the variation of normalized strength and stiffness.

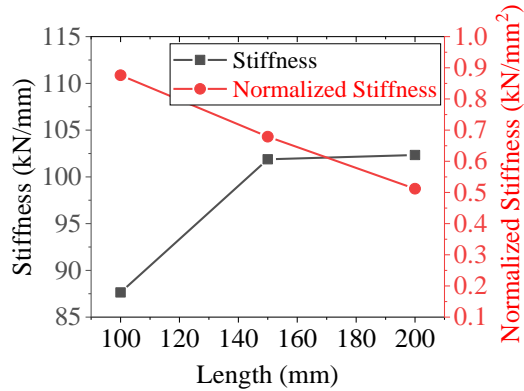

Stiffness of Group 1

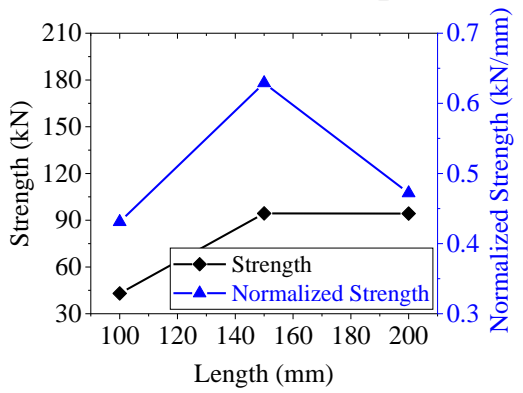

Strength of Group 1

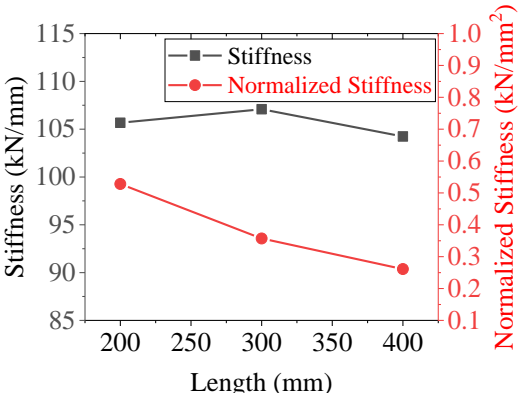

Stiffness of Group 2

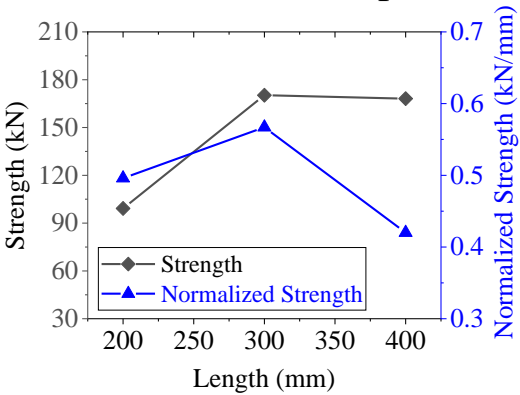

Strength of Group 2

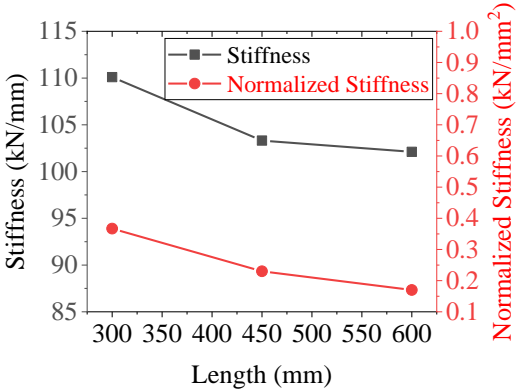

Stiffness of Group 3

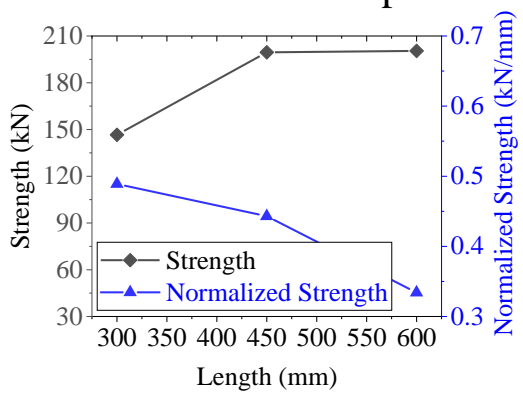

Strength of Group 3

Figure 4. Stiffness and strength of the joint changing with the length

Here are some observations from Table 4 and Figure 4:

(1) Since concrete has a low tensile strength (5MPa in this study), the concrete tensile cracking usually happens first, but the load-carrying capacity of the connection would still increase until a governing failure mode (concrete shear failure, timber shear failure or timber compression failure) triggers the failure. In some cases, if the connection has a very short timber length (Connection 1-1 and 2-1), the timber shear failure would happen first without obvious cracks in concrete.

(2) When the concrete is relatively weak compared to timber, a crack due to tension will develop first in the concrete protrusion followed by the shear failure of concrete, as shown in Figure 5. This two-step failure mode of concrete observed from this study coincided well with the analytical model proposed by Kaneko et al. (1993).

(3) When concrete protrusion is relatively strong, timber in front of the notch will fail ahead of concrete. If the timber length is small, the failure mode of timber will be timber shear failure. If the timber is long enough, the failure mode will be timber compression failure.

(4) The stiffness is nearly constant for all connections except for connection1-1. In terms of strength, longer connections tend to have higher strength.

(5) Since shorter connections can have almost same stiffness and strength as longer connections, the normalized stiffness and normalized strength seem to be better indicators of the efficiency of the shear connectors. Results in Table 3 show that 
connection 1-1 and 1-2 have the highest normalized stiffness and normalized strength respectively.

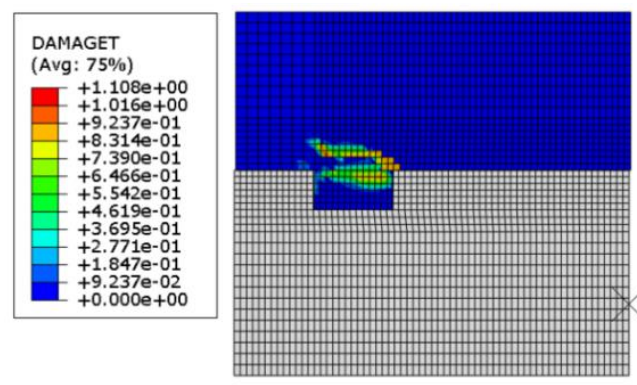

Figure 5. Concrete failure pattern in connection 1-3

\section{FINITE ELEMENT MODELING OF MTPC COMPOSITE BEAMS WITH NOTCHED CONNECTIONS}

The efficiency of the notched connections with different sizes are further examined in the MTPC composite beams. Four models of MTPC composite beams connected by notched connections 12, 2-2, 3-2 and 3-3 respectively are built in ABAQUS. The spacing for the notched connections in four beams are $150 \mathrm{~mm}, 300 \mathrm{~mm}, 450 \mathrm{~mm}$ and $600 \mathrm{~mm}$ respectively. The total span of the beams is $3700 \mathrm{~mm}$. The beams are simply-supported and uniformly distributed load is applied on the top surface. Only half beam model with symmetric boundary condition is applied for simplicity. The material properties of timber and concrete and the thickness and width of two layers in the beam models are the same as connection models.

The obtained load-deflection at mid-span curves of the four beams together with beams that have full composite action and no composite action are drawn in Figure 6. Some previous studies showed that the notched connection can be very stiff and full composite action can be assumed. In this study, probably because no mechanical connectors are used to strengthen the connection and prevent uplifting of concrete, only partial composite action can be reached. Figure 6 shows that beams with notched connections in a smaller spacing have higher composite action than beams with notched connections in a larger spacing.

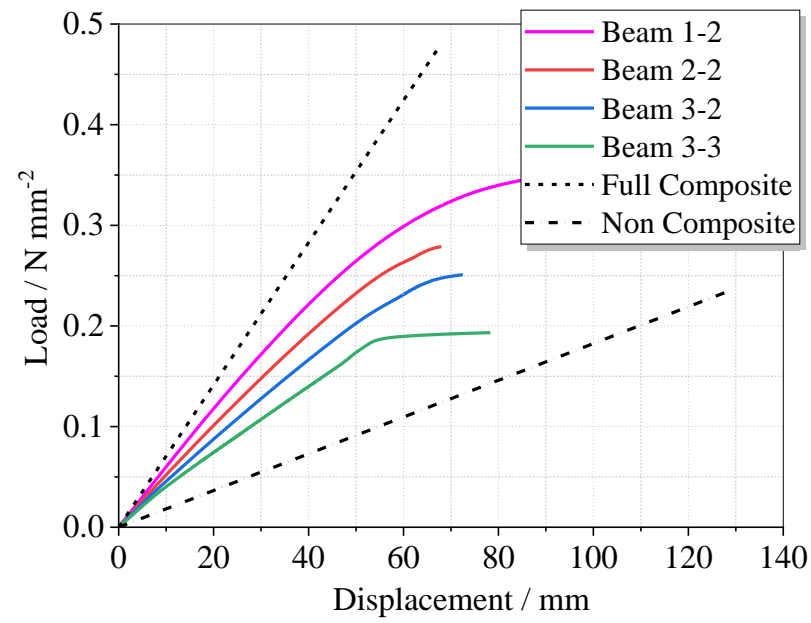

Figure 6. Load-displacement curves of beams with different stiffness 
The failure modes of the composite beams are listed in Table 5 and some typical failure modes are also shown in Figure 7. A noteworthy observation is that the behaviour of the notched connection under shear and under bending are not exactly the same. An example is that, connection 3-2 failed due to timber compression in front of the notch under shear load while beam 3-2 failed due to timber shear failure under bending. Figure 7(b) also shows that when the connections are stronger compared with timber and concrete layers, such as beam 1-2, one of these two layers will fail first prior to the failure of connections.

Table 5. Stiffness and failure modes of the composite beams

\begin{tabular}{|c|c|c|c|c|c|}
\hline \multirow{3}{*}{ Beam } & \multicolumn{4}{|c|}{$\mathrm{EI}\left(\mathrm{kN} \mathrm{m}^{2}\right)$} & \multirow{3}{*}{ Failure mode } \\
\hline & \multicolumn{2}{|r|}{$\mathrm{FE}$} & \multirow{2}{*}{$\begin{array}{l}\text { Gamma } \\
\text { method }\end{array}$} & \multirow{2}{*}{$\begin{array}{l}\text { Strut } \\
\& \text { tie }\end{array}$} & \\
\hline & Initial & Serviceability & & & \\
\hline $1-2$ & 2942 & 2797 & 3014 & 2938 & $\begin{array}{l}\text { Concrete cracked first at the notched regions, } \\
\text { followed by concrete crushing at top of the beam, } \\
\text { then timber shear-off failure at the end joint, and } \\
\text { finally timber tension failure at bottom of the beam }\end{array}$ \\
\hline $2-2$ & 2576 & 2390 & 2731 & 2617 & $\begin{array}{l}\text { Concrete cracked first at the notched region, then } \\
\text { timber shear-off failure at the end joint, followed by } \\
\text { minor crushing of concrete at top of the beam }\end{array}$ \\
\hline $3-2$ & 2297 & 2042 & 2483 & 2334 & $\begin{array}{l}\text { Concrete cracked first at the notched regions, then } \\
\text { timber shear-off failure at the end joint, followed by } \\
\text { minor crushing of concrete at top of the beam }\end{array}$ \\
\hline $3-3$ & 2044 & 1687 & 2297 & 2077 & $\begin{array}{l}\text { Concrete cracked first at the notched area, then } \\
\text { timber compression failure at the end joint }\end{array}$ \\
\hline
\end{tabular}

The effective bending stiffness of the beams could be determined from Equation (5)

$$
\delta=\frac{5}{384} \frac{q l^{4}}{E I}
$$

Two stiffness properties have been calculated from this relation for each beam, the initial stiffness (0-10\% peak load) and the serviceability stiffness (10\%-40\% peak load), and results are listed in Table 5. As can be seen, the serviceability stiffness decreases significantly from the initial stiffness, suggesting that the nonlinearity of the composite beam started at an early stage. This nonlinearity may come from cracking of concrete, opening of gaps between two layers, etc.

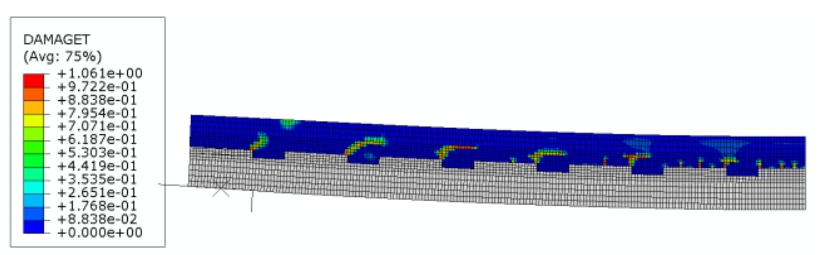

(a) Tensile cracking of concrete in beam 2-2

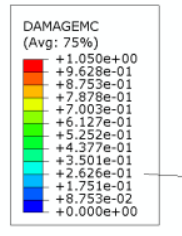

(c) Timber shear failure in beam 2-2

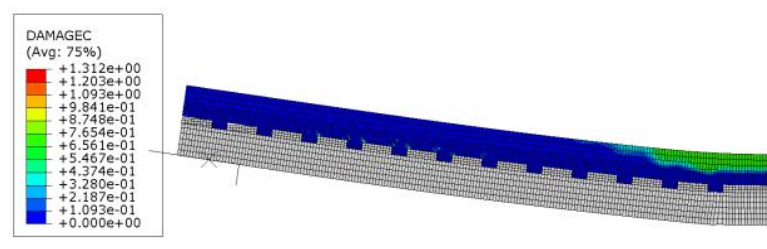

(b) Concrete crushing failure in beam 1-2

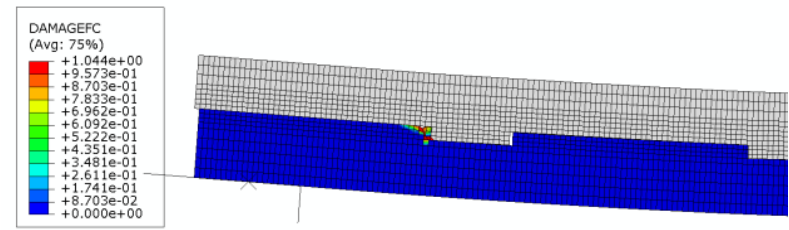

(d) Timber compression failure in beam 3-3

Figure 7. Some Typical failure modes of the composite beams 
MOC SUMMIT / MAY 2019

\section{VERIFICATION OF THE FINITE ELEMENT RESULTS}

\section{Gamma method}

A well-known design method for predicting the stiffness and internal forces of the composite beams at elastic stage is the Gamma method from Eurocode 5 (2006). The effective bending stiffness of the composite beam according to Gamma method can be calculated as

$$
(E I)_{e f f}=E_{c} I_{c}+E_{t} I_{t}+\gamma E_{c} A_{c} a_{c}^{2}+E_{t} A_{t} a_{t}^{2}
$$

where

$$
\begin{gathered}
\gamma=\left(1+\frac{\pi^{2} E_{c} A_{c}}{k l^{2}}\right)^{-1} \\
a_{t}=\frac{\gamma E_{c} A_{c}}{\left(\gamma E_{c} A_{c}+E_{t} A_{t}\right)} \frac{h}{2} \\
a_{c}=\frac{h}{2}-a_{t}
\end{gathered}
$$

In Equation (7), $k$ is the normalized stiffness of the joint and $l$ is the beam span. Subscripts $c$ and $t$ represent concrete and timber respectively. The effective bending stiffness obtained from Equation (6) are shown in Table 5. A significant overestimation of the stiffness is observed using Gamma method especially when the spacing of the connections is large. The main reason that Gamma method gives an overestimation of the stiffness is that, this method is derived based on the assumption that connectors between timber and concrete are continuous or closely spaced. The notched connections do not properly fall into this category. This result indicates that Gamma method is not accurate for predicting the behaviour of discrete connectors such as notched connections in MTPC composite systems.

\section{Strut-and-tie model}

Strut-and-tie model is a simplified model to model composite structures in software and is first proposed by Grosse et al. (2003). It models timber and concrete as single cross section beams and connecting them with short elements represents connectors. As shown in Figure 8, the distance between timber beam and concrete beam is the distance between centroids of both elements, which is $115 \mathrm{~mm}$ in this study. The timber and concrete beams are connected by hinged rigid truss elements with a spacing of $100 \mathrm{~mm}$ to get the same vertical deformation of both beams. At the positions of the notched connections where timber and concrete squeeze each other, the shear resistance is modeled by two cantilevers connected by a hinge. The bending stiffness of the cantilever is adjusted as

$$
E I=\frac{K}{3} \cdot\left(e_{1}^{3}+e_{2}^{3}\right)
$$

where $K$ is the stiffness of the connections and $e_{1}$ and $e_{2}$ are the distance between the centroid of the concrete and timber to the joint which are $62.5 \mathrm{~mm}$ and $52.5 \mathrm{~mm}$ respectively in this study. Only half of the composite beam is built using strut-and-tie model in ABAQUS and symmetric boundary condition is applied. The stiffness of the composite beams under uniformly distributed load are calculated from Equation (5) and are shown in Table 5. As can be seen, since only the elastic analysis is carried out using strut-and-tie model, the obtained stiffness is very close to the initial stiffness obtained from FE models with solid elements. 


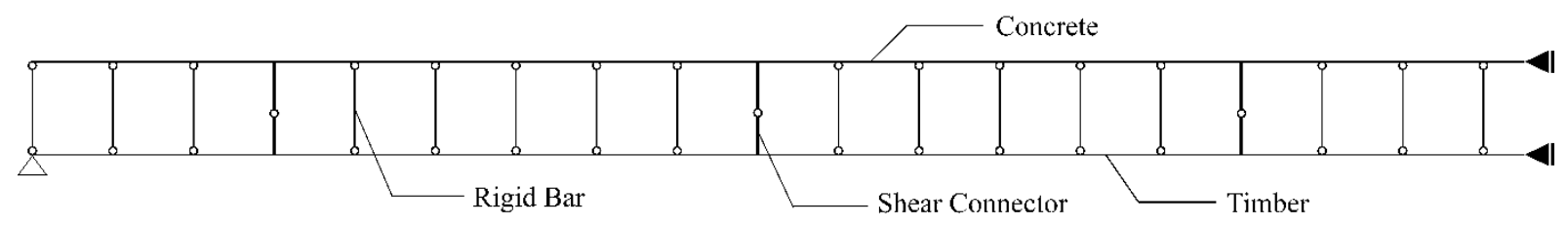

Figure 8. Strut-and-tie model

However, since the serviceability stiffness of the composite beam is significantly lower than its initial stiffness, the nonlinearity of the composite beam should be considered in the analysis. Although the strut-and-tie model shows a better estimation of the initial stiffness of the composite beams than the Gamma method, it seems very difficult to simulate the nonlinearity using strut-and-tie model since it is not capable of modeling concrete cracking or gap opening and also because the behaviour of the notched connection under shear observed in this study is almost linear up to the failure.

\section{CONCLUSIONS}

The following conclusions could be drawn from this study

(1) The effectiveness of the Mass timber panel-concrete composite beams is significantly affected by the geometry of the notched connections. Beams with denser notched connections tend to have higher composite action.

(2) The normalized stiffness and strength are better indicators of the effectiveness of the notched connections than their absolute values of stiffness and strength.

(3) The failure mode of the composite beam with notches under bending is also significantly affected by the size of the notched connections. When the notched connections are overdesigned, the concrete layer or timber layer will fail before the failure of the notched connection.

(4) The nonlinearity is an important characteristic of the composite beam with notches under bending and should be taken into consideration in the composite beam design.

This study only investigated the effect of the groove length and timber length in the notched connections. Other geometry factors such as the depth and shape of the notch should be investigated in future studies.

\section{REFERENCES}

BS EN 1995-1-1 Eurocode 5 (2006): Design of timber structures; British Standards Institute (BSI).

Comité Européen de Normalisation (CEN). (1991). "Timber structures - Joints made with mechanical fasteners - General principles for the determination of strength and deformation characteristics." EN 26891, Brussels, Belgium.

Dias, Alfredo MPG, et al (2018). "Performance of dowel-type fasteners and notches for hybrid timber structures." Engineering Structures 171: 40-46.

Forest Products Laboratory (2010). "Wood handbook - Wood as an engineering material." General Technical Report FPL-GTR-190, Department of Agriculture, Forest Service, USA.

Grosse, M., et al (2003): Modellierung von diskontinuierlich verbundenen Holz-BetonVerbundkonstruktionen. Bautechnik 80, pp. $534-541$ and $693-701$. 
Hashin, Z. (1980). "Failure criteria for unidirectional fiber composites." Journal of applied mechanics 47.2: 329-334.

Hsu, L. S., and C-TT Hsu (1994). "Complete stress-strain behaviour of high-strength concrete under compression." Magazine of concrete research 46.169: 301-312.

Kaneko Y., et al (1993). Fracture mechanics approach for failure of concrete shear key. I: Theory. Journal of engineering mechanics, 119(4): 681-700.

Wahalathantri, B. L., et al (2011). "A material model for flexural crack simulation in reinforced concrete elements using ABAQUS." Proceedings of the first international conference on engineering, designing and developing the built environment for sustainable wellbeing. Queensland University of Technology.

Yeoh, D., et al (2010). "State of the art on timber-concrete composite structures: Literature review." Journal of structural engineering 137.10: 1085-1095. 